\title{
The Importance of Posture and Gravity in the Pathophysiology of Obstructive Sleep Apnea "Because of an Elephantiasis Case with Sleep Disordered Breathing"
}

\author{
Murat Kayabekir ${ }^{1,2 *}$ \\ ${ }^{1}$ Regional Training and Research Hospital, Sleep Disorders Center, Electrophysiology Lab, Erzurum, Turkey \\ ${ }^{2}$ Department of Physiology, Medical School, Ataturk University, Erzurum, Turkey
}

*Corresponding author: Murat Kayabekir, MD, PhD, Regional Training and Research Hospital, Sleep Disorders Center, Electrophysiology Lab; Department of Physiology, Medical School, Ataturk University, Erzurum, Turkey, Tel: 905327356836

\begin{abstract}
The objective of drafting this case report is to delineate the relationship between elephantiasis disease rarely encountered in clinical practice and sleep disordered breathing, to try to understand how this specific condition influences the quality of sleep, to review the mechanisms for Obstructive Sleep Apnea Syndrome which is the most common sleep disordered breathing seen and to underline its importance once again. Lymphedema is a chronic condition stemming from the insufficient drainage of interstitial tissue fluid by lymphatic vessels resulting in swelling of lower extremities and increase in body weight. It limits the movement capacity of the individual leading to "long term disability". Thus, weight gain related obesity and sleep disordered breathing trigger each other; the patient who already experiences problems due to elephantiasis is also confronted by the systemic problems posed by narrowing of the upper respiratory airways and severe sleep apnea syndrome.
\end{abstract}

\section{Keywords}

Sleep quality, Lymphatic drainage impairment, Obesity, Polysomnography, SDB, OSAS pathophysiology

\section{Introduction}

Lymphedema is a chronic condition where there is swelling of the lower extremities due to insufficient drainage of interstitial tissue fluid by lymphatic vessels. When no cause can be found in certain cases, it is classified as idiopathic. However, there are forms seen due to parasitic, chemical and sexually transmitted factors. In most cases of lymphatic filariasis, the causative agent is
Wuchereria bancrofti. It has a widespread distribution encompassing tropical and subtropical regions of the world, Asia and Pacific Islands, Africa, South America and Caribbean Islands. Many individuals are thought to have been infected in these regions. The disease can as well be caused by Brugia malayi and B. Timori in Asia. It is transmitted to human beings by infected mosquitoes. In Turkey, except for a few rare cases thought to be of Asian and African origin, new cases have not been reported. Most of the patients are asymptomatic. The symptoms appear due to the damage in the lymphatic vessels. Clinical signs develop very slowly. When lymphatic system is blocked, edema specifically accumulates in feet and genital region and these tissues get thicker. Therefore, the disease is called elephantiasis $[1,2]$. The lower extremities of the body namely the scrotum, the labia pudenda and the mammae are more frequently affected than the upper ones. So, there is a significant weight gain in the lower portion of the body, the movement capacity of the individual is limited, and obesity appears by itself. Obesity triggers the sleep disordered breathings (SDBs) namely snoring and sleep apnea. SDBs are frequent in the general population. Simple snoring, upper respiratory airways resistance syndrome, obstructive sleep apnea syndrome (OSAS) are frequently encountered problems during sleep. In the society, one out of four individuals have the risk to develop OSAS. In OSAS; because of the obstructions in the upper respiratory airways during sleep, there

\footnotetext{
Citation: Kayabekir M (2018) The Importance of Posture and Gravity in the Pathophysiology of Obstructive Sleep Apnea "Because of an Elephantiasis Case with Sleep Disordered Breathing". Int J Respir Pulm Med 5:096. doi.org/10.23937/2378-3516/1410096

Accepted: November 17, 2018; Published: November 19, 2018

Copyright: (C) 2018 Kayabekir M. This is an open-access article distributed under the terms of the Creative Commons Attribution License, which permits unrestricted use, distribution, and reproduction in any medium, provided the original author and source are credited
} 
are repetitive respiratory problems (Apnea: stopping of respiration during sleep for 10 seconds or longer; Hypopnea: decrease in respiration for 10 seconds or longer during sleep); both are clinical instances where respiratory effort is increased, and this is an important health problem affecting several body systems. The prevalence of OSAS is high after 65 years of age $[3,4]$.

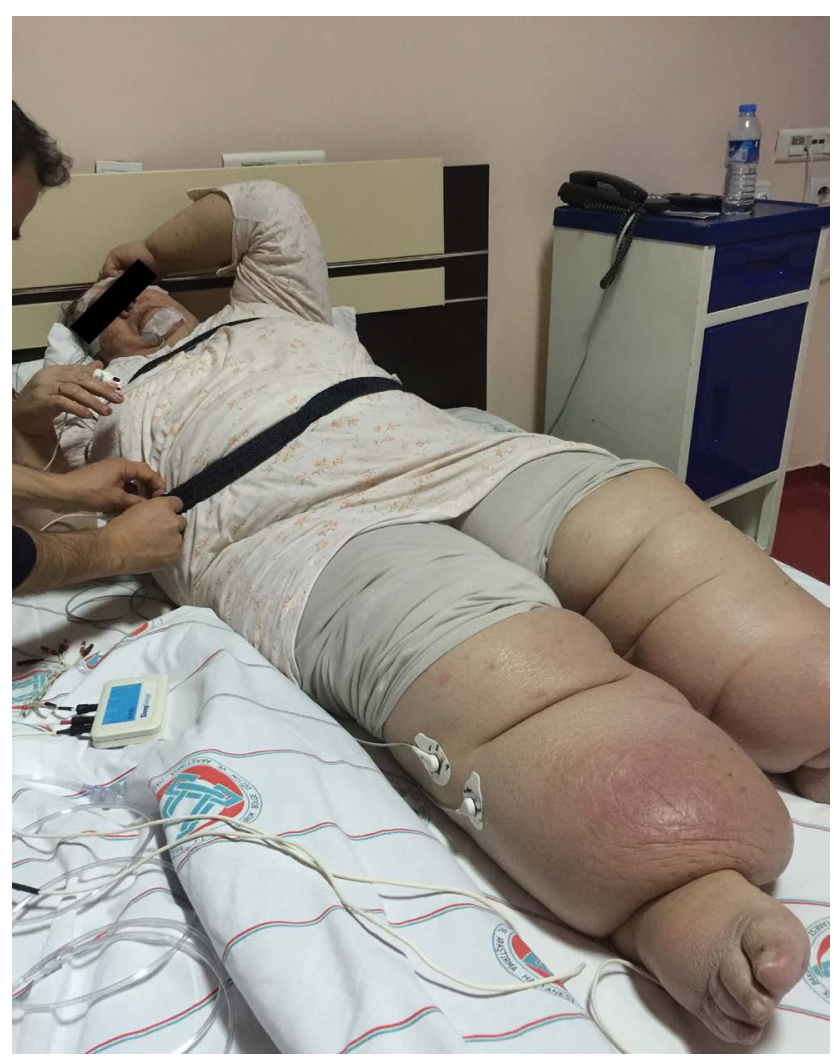

Figure 1: The case of elephantiasis prepared by technician for polysomnography recording.
Obesity increases the risk for OSAS. OSAS is seen two times higher in men compared to women. Other risk factors are soft tissue anomalies of the craniofacial region and upper respiratory airways, genetic factors, nasal obstructions, smoking, nasal congestion and pregnancy [5-8]. By drafting this case report, we aim at demonstrating the co-presence of elephantiasis and SDB and to make an attempt once again to understand the mechanism underlying OSAS.

\section{Report}

Case Y.G, female, 65-years-old, $152 \mathrm{~kg}, 150 \mathrm{~cm}$, BMI: $66 \mathrm{~kg} / \mathrm{m}^{2}$ (Morbid Obese). Y.G. (Figure 1), is being followed up with the diagnosis of elephantiasis for the last ten years. Polysomnography was performed based on complaints of excessive sleepiness during day time, snoring and witnessed apnea; the related data is presented on Table 1.

Nocturnal oxygen saturation was between 51 and 79.3 intervals. It has remained in the interval of oxygen saturation during sleep that in $145 \mathrm{~min} 80 \%-89 \%$, in 151.4 min 70\%-79\% (Table 2).

In blood chemistry analysis, the lipid profile of the patient was mildly elevated while other parameters were normal (Table 3). There is no other medication use other than antihypertensives. The patient could not tolerate CPAP. She had IPAP:15/EPAP: $11 \mathrm{~cm} \mathrm{H}_{2} \mathrm{O}$, altered respiratory parameters during sleep normalized with bi-level PAP application.

\section{Discussion}

Weight gain is inevitable in individuals who cannot

Table 1: Polysomnographic results (The number of the respiratory events, position and sleep stages).

\begin{tabular}{|l|l|l|l|l|l|}
\hline & \multicolumn{2}{l|}{ According to sleep stage } & \multicolumn{2}{l|}{ According to position } & \multicolumn{2}{l|}{ Total } \\
\cline { 2 - 6 } & NREM & REM & Non-supine & Supine & \\
\hline Sleep Time (min.) & 198 & 27.5 & 168 & 57.5 & 225.5 \\
\hline Obstructive apnea & 161 & 27 & 61 & 127 & 188 \\
\hline Mix apnea & 0 & 0 & 0 & 0 & 0 \\
\hline Central apnea & 0 & 0 & 0 & 0 & 0 \\
\hline All apneas & 161 & 27 & N/A & 127 & 188 \\
\hline Hypopneas & 204 & 10 & 197 & 17 & 214 \\
\hline All apnea + hypopneas & 365 & 37 & 258 & 144 & 402 \\
\hline Apnea index & 48.8 & 58.9 & 21.8 & 132.5 & 50 \\
\hline Hypopnea index & 61.8 & 21.8 & 70.4 & 17.7 & 56.9 \\
\hline A/H INDEX & 110.6 & 80.7 & 92.1 & 150.3 & 107 \\
\hline
\end{tabular}

Table 2: Nocturnal mean $\mathrm{O}_{2}$ saturation.

\begin{tabular}{|c|c|c|c|c|}
\hline & Awaking & NREM & REM & Total \\
\hline Min $\mathrm{O}_{2}$ saturation (\%) & 51 & 58 & 54 & 51 \\
\hline Max $\mathrm{O}_{2}$ saturation $(\%)$ & 96 & 89 & 81 & 96 \\
\hline Mean $\mathrm{O}_{2}$ saturation (\%) & 85.1 & 77.9 & 67.6 & 79.3 \\
\hline Time $90 \%-100 \%$ (min.) & 0.2 & 0 & 0 & 0.2 \\
\hline Time $80 \%-89 \%$ (min.) & 93.3 & 51.9 & 0.1 & 145.2 \\
\hline Time $70 \%$ - 79\% (min.) & 6.5 & 135.4 & 9.5 & 151.4 \\
\hline Time $60 \%-69 \%$ (min.) & 0.1 & 10.5 & 13.9 & 24.5 \\
\hline Time $50 \%-59 \%$ (min.) & 0 & 0.3 & 4.1 & 4.3 \\
\hline Süre $\leq 88 \%$ (min.) & 97.5 & 198 & 27.5 & 323.0 \\
\hline
\end{tabular}


Table 3: Biochemical results.

\begin{tabular}{|l|l|l|l|}
\hline Marker & Result & Unit & Reference range \\
\hline Albumin & 4.15 & $\mathrm{~g} / \mathrm{dL}$ & $3.5-5.0$ \\
\hline AST & 14 & $\mathrm{U} / \mathrm{L}$ & $5-34$ \\
\hline ALT & 17 & $\mathrm{U} / \mathrm{L}$ & $0-55$ \\
\hline Cholesterol & 221 & $\mathrm{mg} / \mathrm{dL}$ & $0-200$ \\
\hline LDL-Cholesterol & 138 & $\mathrm{mg} / \mathrm{dL}$ & $0-120$ \\
\hline HDL-Cholesterol & 51.84 & $\mathrm{mg} / \mathrm{dL}$ & \\
\hline Triglyceride & 108 & $\mathrm{mg} / \mathrm{dL}$ & $<150$ \\
\hline Protein & 7.24 & $\mathrm{~g} / \mathrm{dL}$ & $6.0-8.3$ \\
\hline CRP & 1.25 & $\mathrm{mg} / \mathrm{dL}$ & $0-5$ \\
\hline
\end{tabular}

move. Elephantiasis is known as the most developed form of lymphedema, it results in limitations in the individual's movement ability leading to "long term disability" and obesity. In fact, immobility, obesity and breathing problems in sleep appear together as a result of long-lasting impairments in lymphatic drainage. Abdominal obesity and a neck circumference of more than $40 \mathrm{~cm}$ are regarded as predisposing factors for OSAS (5-8). Pathophysiologically, airway obstruction and closure seen during sleep in OSAS takes place in retropalatal and retroglossal regions $[9,10]$. For the preservation of upper respiratory airway patency, there needs to be a balance of two important physiological mechanisms: (a) Forces causing the collapse of pharyngeal airways (amount of soft tissues surrounding the airways and the size of the airway); (b) Forces dilating the pharyngeal airways (the activity of a muscle group that work in a coordinated manner to keep the airways open) [10-12]. Predisposing factors that cause the disruption of this balance are: "Mainly age and sex to be followed by race, obesity, neck circumference, smoking, alcohol-sedative use, genetic factors, comorbid disease states (acromegaly, hypothyroidism, Down Syndrome, storage diseases like amyloidosis and mucopolysaccharidosis) posture and gravity, anatomical factors, genetic factors and hormones [68]". Long lasting immobility and obesity in rarely seen elephantiasis case negatively influences the movements of all the muscles in the body including the pharyngeal muscles responsible for the patency of the upper respiratory airways. Neurophysiological mechanisms (nerves innervating these muscles and striated muscles) responsible for the existence of an important passage allowing for the transfer of air in the upper respiratory airways cannot function adequately. Thus, breathing disorders like snoring and OSA appear during sleep. The shape and structure of the upper respiratory airways is related to the position of the soft tissue component affected by gravity. In dorsal decubitus position, the tongue and soft palate move backwards resulting in the narrowing of the oropharyngeal field [13-15]. The elephantiasis case reported here could not maintain upper airway patency during sleep. When factors leading to the collapse of pharyngeal airways are considered, we see that our patient is obese; changed posture due to the specifically increased body weight around lower extremities and gravity impair the mechanisms responsible for the patency of the upper respiratory airways. From the perspective of etiopathogenesis, the increase in weight in lower extremities has changed the direction and strength of the gravitational forces influencing our elephantiasis patient. Therefore, as concerns the pathophysiological mechanisms for severe OSAS seen in this case, we think that the changes in the position of the soft tissue components significantly affected by gravity disrupted the shape and structure of the upper airways and resulted in sleep apnea of severe degree. The patient is bedbound due to dysfunctions in lymphatic drainage and venous return, the results in this immobile patient demonstrates us that the health of the patient is impaired not only during wakefulness but also during sleep. As our case was bilateral elephantiasis culminating in the lower extremities and she had difficulty in walking. The body weight had shifted towards lower extremity in this morbid obese patient, the resultant apnea and specifically hypopnea she had was attention grabbing. The patient was diagnosed with severe OSAS; when in supine position obstructive type apneas were aggravated while when in lateral position there was an increase in hypopnea. Nearly all hypopneas occurred in the lateral position during sleep (hypopnea count: 197/hour). This resulted in us reconsidering the importance of soft tissue components affected by gravity as well as the shape and structure of upper respiratory airways. When a morbid obese patient of this weight changes from supine position to non-supine, there is an increase in weight in the lower extremities resulting in changes in the strength and direction of gravitational forces changing the shape and structure of the upper respiratory airways. This case clearly demonstrated the importance of posture and gravitational factors on the formation of OSAS. The patient is currently receiving BIPAP treatment during night and special compression therapy and physiotherapy as recommended by infectious diseases department during daytime.

\section{Disclosure Statement}

The author has seen and approved this manuscript. Work for this study was performed at the Sleep Medicine Center, Electrophysiology Laboratory. The author reports no conflicts of interest.

\section{References}

1. Taylor MJ, Hoerauf A, Bockarie M (2010) Lymphatic filariasis and onchocerciasis. Lancet 376: 1175-1185.

2. Özcel A, Özbel Y, Ak M, Kuman HA (2007) Filariasis. In: Özcel's Medical Parasitic Diseases. Parasitology Association of Turkey Publish, Izmir, 601-627.

3. Strohol KP, Redline S (1996) Recognition of obstructive sleep apnea. Am J Respir Crit Care Med 154: 279-289.

4. Valipour A (2012) Gender-related differences in the obstructive sleep apnea syndrome. Pneumologie 66: 584-588.

5. Young T, Skatrud J, Peppard PE (2004) Risk factors for OSA in adults. JAMA 291: 2013-2016. 
6. Kent BD, Grote L, Ryan S, Pépin JL, Bonsignore MR, et al (2014) Diabetes mellitus prevalence and control in sleepdisordered breathing: The European Sleep Apnea Cohort (ESADA) study. Chest 146: 982-990.

7. Varvarigou V, Dahabreh IJ, Malhotra A, Kales SN (2011) A review of genetic association studies of obstructive sleep apnea: Field synopsis and meta-analysis. Sleep 34: 14611468.

8. Strausz S, Havulinna AS, Tuomi T, Bachour A, Groop L, et al. (2018) Obstructive sleep apnoea and the risk for coronary heart disease and type 2 diabetes: A longitudinal population-based study in Finland. BMJ Open 8.

9. Suto Y, Matsou T, Kato T, Hori I, Inoue Y, et al. (1993) Evaluation of the pharyngeal airway in patients with sleep apnea: Value of ultrafast MR imaging. AJR Am J Roentgenol 160: 311-314

10. Cori JM, O'Donoghue FJ, Jordan AS (2018) Sleeping tongue: Current perspectives of genioglossus control in healthy individuals and patients with obstructive sleep apnea. Nat Sci Sleep 10: 169-179.

11. Shelton KE, Gay SB, Hollowell DE, Woodson H, Suratt PM (1993) Mandible enclosure of upper airway and weight in obstructive sleep apnea. Am Rev Respir Dis 148: 195-200.

12. Martins AB, Tufik S, Moura SM (2007) Physiopathology of obstructive sleep apnea-hypopnea syndrome. J Bras Pneumol 33: 93-100.

13. Ayappa I, Rapoport DM (2003) The upper airway in sleep: Physiology of the pharynx. Sleep Med Rev 7: 9-33.

14. Diercks GR, Wentland C, Keamy D, Kinane TB, Skotko B, et al. (2017) Hypoglossal nerve stimulation in adolescents with down syndrome and obstructive sleep apnea. JAMA Otolaryngol Head Neck Surg.

15. Simpson R, Oyekan AA, Ehsan Z, Ingram DG (2018) Obstructive sleep apnea in patients with Down syndrome: Current perspectives. Nat Sci Sleep 10: 287-293. 